\title{
El paisaje lingüístico de la migración en el barrio de Ruzafa en Valencia: una mirada a través del tiempo
}

The Migration Linguistic Landscape in the District of Ruzafa (Valencia): A Glimpse Through Time

ANA GÓMEZ-PAVÓN DURÁN

UNIVERSITAT DE VALÈNCIA

ORCID: https://orcid.org/0000-0002-4291-8763

MERCEDES QUILIS MERÍN

UNIVERSITAT DE VALÈNCIA

ORCID: https://orcid.org/0000-0002-9560-3298

RESUMEN: Esta investigación estudia el paisaje lingüístico del barrio de Ruzafa en Valencia (España), conocido por su carácter multicultural y multilingüístico debido al establecimiento de población migrante en las últimas décadas del siglo $\mathrm{XX}$ y a su transformación en un espacio turístico como consecuencia del proceso de gentrificación en los primeros años del siglo XXI. El objetivo es explorar a través de los signos del paisaje lingüístico los cambios socio-demográficos desde un enfoque diacrónico y contrastivo. La metodología está basada en utilización de la herramienta Google Street View que ha permitido configurar un corpus fotográfico de 212 signos, imágenes de rótulos de comercios privados del barrio, de los años 2008 y 2018. El análisis de las lenguas que aparecen en los signos y cómo se relacionan entre sí nos ha permitido conocer el grado y el tipo de multilingüismo que han aportado al barrio en estos dos puntos de su historia los diferentes grupos de población, especialmente los de origen migrante, y las consecuencias lingüísticas de la gentrificación sobre su paisaje lingüístico.

Palabras clave: Paisaje lingüistico, paisaje lingüistico de la migración, diacronía en paisaje lingüístico, multilingüismo, gentrificación, Google Street View, Ruzafa (Valencia). 
ABSTRACT: This study investigates the linguistic landscape of the district of Ruzafa in Valencia (Spain), which is known for its multicultural and multilingual character due to the settling of migrant communities in the last decades of the 20th century and its transformation into a touristic area as a consequence of a gentrification process that started in the first years of the 21 st century. The aim is to explore, through the analysis of the signs of its linguistic landscape, the socio-demographic changes in the said district from a diachronic and contrastive approach. Our methodology is based on the use of Google Street View, which has enabled the configuration of a photographic corpus that contains 212 images of signs from private businesses from the years 2008 and 2018. The analysis of the languages that appear in the signs and of how they are related to each other has allowed us to learn the degree and type of multilingualism that the different population groups, especially those of migrant origin, have contributed to the district at these two points in its history, and the linguistic consequences of gentrification in its linguistic landscape.

Key words: Linguistic Landscape, Migration Linguistic Landscape, diachrony in Linguistic Landscape, Google Street View, multilingualism, gentrification, Ruzafa (Valencia).

\section{INTRODUCCIÓN. RUZAFA, UN BARRIO MULTILINGÜE}

El barrio de Ruzafa, castellanización de su nombre valenciano y oficial, Russafa, en pleno centro de la ciudad española de Valencia, es una de las zonas más populares de la ciudad con una historia que despierta un interés no solo a nivel social, demográfico o económico, sino también lingüístico. La presencia prolongada de población extranjera en Ruzafa en las últimas décadas ha sido el motivo de que sea considerado por los ciudadanos valencianos como un barrio multicultural y multilingüe. En la última década, esta área urbana ha experimentado una profunda transformación que se ha consumado en diferentes fases: el barrio popular y tradicional valenciano que fue Ruzafa inicialmente (Bartual, 2016: 163) pasó a convertirse en una zona problemática y en decadencia debido al proceso de abandono y despoblamiento que sufrió entre los años 60 y 70 del siglo pasado (Torres, 2006; 2007) con el cierre de los negocios y tiendas locales. Sin embargo, a partir de los años 80 el barrio comenzó a ser repoblado por nuevos habitantes de origen migrante que, atraídos por la oferta de vivienda barata y la localización óptima del barrio, se establecieron allí y contribuyeron a su recuperación y crecimiento con la apertura de nuevos comercios:

[...] en las calles Cuba y Dénia, la zona más modesta del barrio, abrieron entre 1990 y 1992 los primeros bazares y una carnicería halal que abastecían a los vendedores ambulantes y a los vecinos magrebíes. La existencia de compatriotas asentados reforzada por una oferta de servicios propios generó un efecto llamada [...] En un primer periodo, la década de los 90, un número reducido de marroquíes, chinos y argentinos se asientan como vecinos, en un proceso lento y discreto. En un segundo período, en el que nos encontramos desde el inicio del siglo, el proceso se acelera con un aumento sustancial del número de vecinos extranjeros, que pasan de 548 en enero de 
2000 , el 2,4 \% del total del vecindario, a 4.036 en enero de 2005, el 15,9 \%. En estos años, el protagonismo corresponde a la inmigración latinoamericana, fundamentalmente ecuatoriana y colombiana, y en menor medida, a los nacionales de Europa del Este.

(Torres, 2006: 6-7)

Sin embargo, la presencia de población inmigrante se ha visto disminuida en los últimos diez años debido principalmente al proceso de gentrificación que ha atravesado esta zona de la ciudad. El fenómeno de la gentrificación, «un proceso de transformación urbana, en el que la población original de un sector o barrio deteriorado y con pauperismo se renueva mediante el progresivo desplazamiento por parte de otra de un mayor nivel adquisitivo»" (Bartual, 2016), se inició en Ruzafa aproximadamente en el año 2007 como consecuencia de la aplicación de un plan de reurbanización y mejora de las condiciones del barrio que provocó el encarecimiento de los alquileres y el consecuente desplazamiento de la población de origen migrante a otras zonas de la ciudad (Romero y Lara, 2015: 188). En efecto, el conjunto de datos demográficos que ofrece la Oficina de Estadística del Ayuntamiento de Valencia confirma para el año 2008 que la población de Ruzafa superaba los 25.000 habitantes con un 17,9\% de procedencia extranjera de los cuales un grupo mayoritario era original de América del Sur, seguido de grupos procedentes de países de la Unión Europea, África y Asia, mientras que los datos correspondientes a 2018 presentan un cambio perceptible en Ruzafa en el momento en el que se realizó este estudio, con un total de 23.834 habitantes de los cuales un 13,3\% eran de origen extranjero, un porcentaje menor al que observábamos en 2008. En 2018, además, la configuración de la población extranjera del barrio había sufrido un notable cambio: la mayoría procedía ahora de países de la Unión Europea, seguidos por los de origen suramericano y africano, como muestra el gráfico 1.

Gráfico 1. Población extranjera en Ruzafa según región en 2008 y 2018. Fuente: Oficina de Estadística del Ayuntamiento de Valencia (2018)

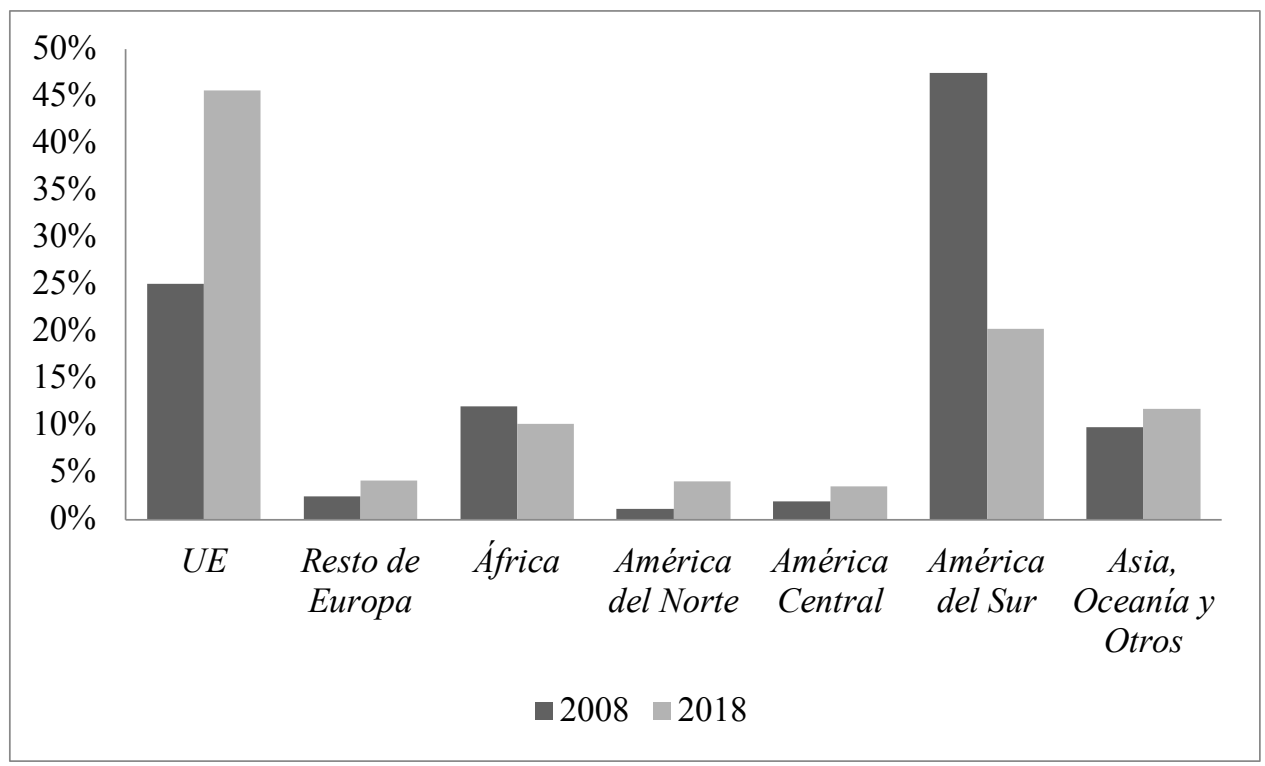

Este conjunto de cambios socio-demográficos sobre la caracterización de los nuevos vecinos emigrantes del barrio de Ruzafa (Torres, 2007), así como el aumento o disminución del grado de presencia de los diferentes grupos étnicos en los últimos treinta años, han tenido una importante repercusión en la realidad lingüística del barrio. En nuestro estudio nos proponemos examinar, a través de la observación de los signos que 
conforman un paisaje lingüístico multilingüístico en Ruzafa, cómo se han producido esos cambios a nivel socio-lingüístico a través del tiempo mediante la visualización en el espacio urbano de la sustitución de las lenguas de los primeros migrantes, con una fuerte presencia en las calles de Ruzafa hasta hace unos años, por las lenguas de los nuevos residentes y por las lenguas preferidas por los nuevos propietarios de los comercios y establecimientos del barrio y sus visitantes, esto es, las lenguas del turismo.

El principal objetivo de este estudio consiste en explorar en detalle la riqueza lingüística que aportan los grupos de origen migrante al repertorio lingüístico de un área urbana concreta y analizar de qué forma han repercutido los fenómenos de la migración y la gentrificación en el entramado lingüístico que se podía apreciar en las calles de Ruzafa en los últimos años. Mediante una orientación diacrónica en los estudios de PL, poco explorada hasta el momento, y el uso de la herramienta Google Street View, que permite recoger imágenes distanciadas en el tiempo, como novedades metodológicas. La descripción de la relación entre el PL y la migración, así como los modelos teóricos y metodológicos que se han empleado en este estudio se establecen en (2). En (3) desarrollaremos la metodología a través de la observación del Paisaje Lingüístico de Ruzafa, tomando a partir de Google Street View imágenes de los rótulos de algunos comercios privados confrontando los años 2008 y 2018. La descripción y análisis del corpus se presenta en (4). La perspectiva diacrónica y contrastiva permite establecer en (5) una valoración final de la situación lingüística del barrio a finales de su etapa de inmigración, por un lado, con el panorama que encontramos en pleno desarrollo de la fase de gentrificación, por otro. Con todo ello, mediante el análisis de los signos del PL como imágenes distanciadas en el tiempo, se pretende demostrar que este tipo de procesos demográficos como el experimentado por el barrio de Ruzafa no afectan solo a nivel económico y social sino también a nivel lingüístico, de modo que un estudio sociolingüístico de estas características complementa el análisis demográfico o socioeconómico del barrio.

\section{PAISAJE LINGÜÍSTICO, MIGRACIÓN Y PERSPECTIVA DIACRÓNICA}

El concepto de linguistic landscape (paisaje lingüístico, en adelante PL) se plantea por primera vez en 1997 en el artículo seminal «Linguistic Landscape and Ethnolinguistic Vitality. An Empirical Study», de Rodrigue Landry y Richard Bourhis con una definición aceptada como canónica en este ámbito de investigación:

The language of public roads, advertising billboards, street names, place names, commercial shops signs, and public signs on government building combines to form the linguistic landscape of a given territory, region or urban agglomeration. The linguistic landscape of a territory can serve two basic functions: an informational function and a symbolic function [...] Linguistic landscape refers to the visibility and salience of languages on public and commercial signs in a given territory or region.

(Landry y Bourhis, 1997: 23, 25)

A partir de este trabajo comienzan a proliferar nuevos estudios sociolingüísticos que se encargan de analizar el PL de diferentes espacios públicos y privados, tomando siempre como unidad mínima de análisis el signo de PL, que Backhaus (2007: 55) define como «any piece of written text within a spatially definable frame», esto es, limitado a signos de los espacios públicos con contenido verbal. El poder y el estatus relativo de los grupos lingüísticos de una comunidad se refleja en PL y muestra su vitalidad etnolingüistica (ethnolinguistic vitality, Landry y Bourhis, 1997: 23) un concepto fundamental en el estudio de poblaciones migrantes, ya que si un idioma de un grupo particular de hablantes puede hallarse en el espacio público en distintos grados de 
visibilidad, o incluso si está ausente, será una muestra determinante de su vitalidad en la sociedad de acogida. La vitalidad etnolingüística dependerá, así, de factores demográficos, políticos, culturales y económicos de cada grupo migrante y establecerá el estatus de las distintas lenguas en convivencia en contextos multilingües. Además del estudio de Backhaus, del que tomamos el concepto de unidad básica de análisis, el signo del PL, encontramos otros trabajos pioneros que contribuyeron al desarrollo de esta nueva disciplina, como el trabajo de Ben-Rafael et al. (2006), sobre Israel y Jerusalén Oriental, donde existe un importante conflicto etnolingüístico, o el análisis del PL de dos ciudades multilingües en San Sebastián y Leeuwarden, en Cenoz y Gorter (2006). Desde entonces, el desarrollo de las investigaciones en la nueva disciplina ha presentado un incremento exponencial en poco más de veinte años de existencia como campo de investigación autónomo en el que se aglutinan distintos enfoques interdisciplinares en el ámbito de las ciencias sociales (sociología, geografía urbana, psicología perceptiva, etnografía o antropología) (Van Mensel, Vanderbroucke y Blackwood, 2016) y, en palabras de Calvi: El éxito de la investigación sobre el PL se explica precisamente en el marco de las actuales, caracterizadas por la diversidad y la hibridación (García Canclini 2001), en las que las lenguas son recursos móviles que generan continuos cambios, a veces difíciles de explicar con los enfoques tradicionales. Es un instrumento adicional para estudiar el plurilingüismo, pero también, más en general, las actividades humanas y los cambios sociales, extendiendo el alcance de la investigación sociolingüística de los grupos de hablantes a los espacios en los que estos se mueven.

(Calvi, 2018: 8)

Asimismo, en la actualidad, este incremento se ha producido también a los estudios dedicados al análisis del PL de diferentes zonas de España, en especial de las grandes ciudades (linguistic cityscape) ${ }^{1}$, tanto en territorios monolingües como bilingües donde la presencia de población y turismo de origen extranjero aporta un carácter multilingüe a su panorama lingüístico. Entre ellos, tras los trabajos de Cenoz y Gorter (2006) para el País Vasco, podemos destacar entre otros los dedicados a Madrid de Castillo y Sáez (2011, 2012), el completo trabajo de Pons (2012) sobre el PL de Sevilla, así como los dedicados a Barcelona (Comajoan, 2013), Almería (Franco-Rodríguez, 2013), Santiago de Compostela (Regueira, López y Wellings, 2013), Málaga (Esteba Ramos, 2014), Mallorca (Bruyèl y Juan Garau, 2015), Zaragoza (Félez, 2017) o Valencia (Ma, 2019) ${ }^{2}$. Han transcurrido siete años desde la primera compilación sobre los paisajes lingüísticos en el mundo hispánico de Castillo y Sáez (2013) en el que ya se presentaba este carácter interdisciplinar de los estudios del PL, más allá de los contenidos y análisis propiamente lingüístico de los signos, y su vinculación con la Lingüística de la migración, que abarca las relaciones entre la lengua y la migración como subdisciplina diferenciada de las lenguas en contacto o la sociolingüística (Zimmermann y Morgenthaler, 2007). Dentro de la Lingüística de la migración, se presta especial atención al PL generado por la población migrante y a los contextos de migración (Ariolfo y Mariottini, 2018) ) $^{3}$ en lo que se ha considerado un aspecto esencial de los efectos generados por la globalización. Así, el creciente interés por el estudio del PL de la migración está motivado por el fenómeno de los desplazamientos migratorios que ha tenido lugar en España en los últimos años, que ha producido un impacto no solo a nivel económico y demográfico, sino también a

\footnotetext{
${ }^{1}$ Para esta denominación, v. Gorter (2013) y Guilat y Espinosa-Ramírez (2016). Para la caracterización del paisaje lingüístico rural y urbano, v. Fernández Juncal (2019).

${ }^{2}$ V. bibliografía actualizada sobre paisajes lingüísticos hispánicos en Calvi (2018: 11-16).

${ }^{3}$ La variedad de enfoques metodológicos para el estudio del PL de la migración fue abordada en el Taller internacional «Paisaje lingüístico de la migración. Un recorrido entre lenguas, teorías y modelos», Roma2016.
} 
nivel lingüístico, pues, como explica Moreno Fernández, «[e]n situaciones de inmigración, la(s) lengua(s) / variedad(es) de los inmigrantes pasan a formar parte del repertorio lingüístico de la comunidad, siempre que tengan un uso social, aunque sea solamente entre los mismos inmigrantes» (2009: 141). Esto significa, por tanto, que es posible encontrar la huella lingüística que deja la población de origen migrante en el PL de muchas zonas del país, y así se han estudiado los signos generados por la población migrante, especialmente las variedades americanas del español en Sevilla (Pons, 2011, 2012) o en Madrid (Castillo y Sáez, 2011) ${ }^{4}$, y también las de otros grupos de población migrante con presencia importante en la capital, como el árabe (Mousatoui, 2013) o el rumano (Muñoz Carrobles, 2013). Para la ciudad de Valencia contamos con el estudio pionero de Calvo (2007) sobre las características de la lengua de los migrantes hablantes de español andino, peruanos y ecuatorianos y también con los trabajos de Ma (2017, 2019) para la lengua y la interlengua en el PL de la comunidad migrante china en el chinatown de la ciudad de Valencia, una zona muy próxima al área de Ruzafa de nuestro estudio. Sumándonos a este interés por el estudio del PL de la migración, este trabajo pretende ofrecer un análisis de los signos del PL generados por la población migrante de diversas procedencias en una zona de Valencia, el barrio de Ruzafa, con un enfoque diacrónico, una perspectiva todavía no explorada en el campo de los estudios de PL en esta ciudad.

El enfoque diacrónico, menos desarrollado en el conjunto de estudios sobre el PL, está indefectiblemente marcado por sus propias características de temporalidad y es necesariamente efímero, una característica que se encuentra tempranamente en estudios que analizan la convivencia entre signos antiguos y modernos en el PL, o que compararan datos de diferentes períodos temporales de manera que se perciban estos cambios (Backhaus, 2006; Pons, 2012; Muñoz Carrobles, 2013). Las enormes posibilidades de un estudio del PL con una perspectiva histórica en el que se cruzan los parámetros de la lengua española de los migrantes procedentes de España o de Hispanoamérica en los años 60 en Lausana (Suiza) es el ofrecido por Castillo Lluch, quien afirma:

The LL of a city makes it possible to read the signs of an immigrant community as evidence of the organisation and the diachronic evolution of its members. [...] This semiotic decoding requires the identification and understanding of the context where such signs $[\ldots]$ were produced.

(Castillo Lluch, 2019: 88)

Esta descodificación semiótica exige la identificación y comprensión del contexto de producción de esos signos y tiene sus precursores en el trabajo de Spolsky (2009) y, fundamentalmente, de Blommaert (2013), quien se basa en la observación directa de los cambios en el PL de su propio barrio de Amberes ${ }^{5}$. En nuestro estudio, hemos asociado los signos actuales con aquellos que ocuparon el mismo lugar, fruto de otras autorías del signo y de otras coyunturas sociodemográficas que se han cuantificado a través de su vitalidad etnolingüística.

Por otra parte, el uso de la herramientas informáticas visuales y videográficas accesibles en internet como Google Street View se han mostrado adecuadas en la investigación sincrónica en PL (Troyer y Szabó, 2017), y así lo ratifica Gorter (2018),

\footnotetext{
${ }^{4}$ Castillo y Sáez (2011: 82) aislaron cinco patrones diferentes de distribución del PL de la migración en la capital (monopoly, gueto, variante progresiva, moteado y PL silencioso) aplicables a otros trabajos que abarcaran el estudio global del PL de una metrópoli. Dada la limitación de nuestro trabajo a un barrio de la ciudad, no tenemos suficientes datos como para aplicar y justificar un patrón de distribución concreto.

${ }^{5}$ Otra orientación de la investigación histórica es la de Guilat y Espinosa-Ramírez (2016) sobre el impacto de la Ley de Memoria Histórica de 2007 en el PL de Granada.
} 
quien opina que es una herramienta que puede ofrecer nuevas e interesantes formas de realizar estudios del PL al hacer accesible la exploración de áreas distantes en todo el mundo. Pero la posibilidad de su utilización en estudios diacrónicos sobre el PL ha sido mucho menos frecuente, pese a que Google Street View no solo brinda una imagen panorámica en $360^{\circ}$, sino que ofrece imágenes almacenadas y accesibles desde el año 2007. El novedoso modelo metodológico para la recolección de datos diacrónicos cuantitativos y cualitativos basado en el empleo de Google Maps y Google Street View establecido por Rosa (2016: 20) en su estudio sobre el impacto del turismo en el PL de Valparaíso ${ }^{6}$ ha construido nuestra referencia en procedimiento que se ha mostrado valioso para el estudio de la evolución del PL de la migración de Ruzafa.

\section{METODOLOGÍA}

Para llevar a cabo este estudio a partir de los datos demográficos migratorios en el barrio de Ruzafa (Gráfico 1), y conociendo los procesos socioeconómicos que han afectado a la zona estudiada, se ha elaborado un corpus integrado por un total de 212 fotografías de signos del PL, de las cuales 106 fueron tomadas por el equipo de Google Street View en agosto de 2008 y otras 106 en junio de 2018. Las imágenes fueron extraídas de Google Street View entre los meses de febrero y junio de 2019. El objetivo de recoger imágenes de dos puntos temporales con una diferencia de diez años era aportar una perspectiva diacrónica y contrastiva al estudio para poder apreciar los cambios en el PL de la zona estudiada. A modo de ejemplo, las imágenes del 2018 muestran los rótulos de algunos locales de Ruzafa que en ese momento se hallaban en el mismo lugar en el que aparecían los signos del año 2008 (ejemplo en figuras 1 y 2). Aunque es posible encontrar casos en los que el local se ha mantenido y no ha habido ningún cambio en la rotulación de este, en la mayoría de los casos sí que se observa un signo con características diferentes a las que aparecían anteriormente.

Figura 1. Rótulo en la calle Cuba, 3 del Bazar El Fath Merakech (2008). En árabe: Bazar EI Fath ('la conquista'), Marrakech

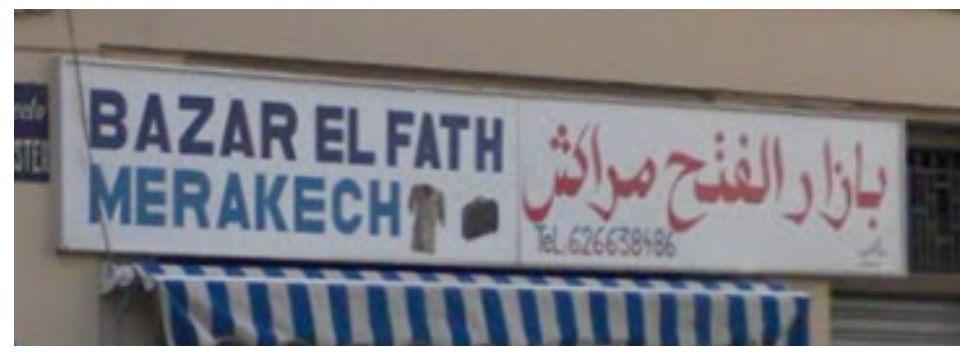

\footnotetext{
${ }^{6}$ Rosa afirma: «La metodología de recolección de datos utilizada en esta tesis [...] permite una rápida creación de cuerpos con información lingüística de distritos, barrios o, con fondos y tiempo suficientes, hasta de ciudades enteras. También brinda la posibilidad de un posterior análisis desde una perspectiva sincrónica y/o diacrónica. Por lo tanto, se abren posibilidades nuevas de investigaciones del impacto de un sinfín de factores en los paisajes lingüísticos») (2018: 108). Para el uso de esta herramienta como fuente no secundaria en el PL de Seúl con perspectiva diacrónica, v. Hong (2020).
} 
Figura 2. Rótulo del estudio de diseño FreeZia en la calle Cuba, 3 (2018). Más abajo se puede leer diseño, creatividad, arte, gourmet

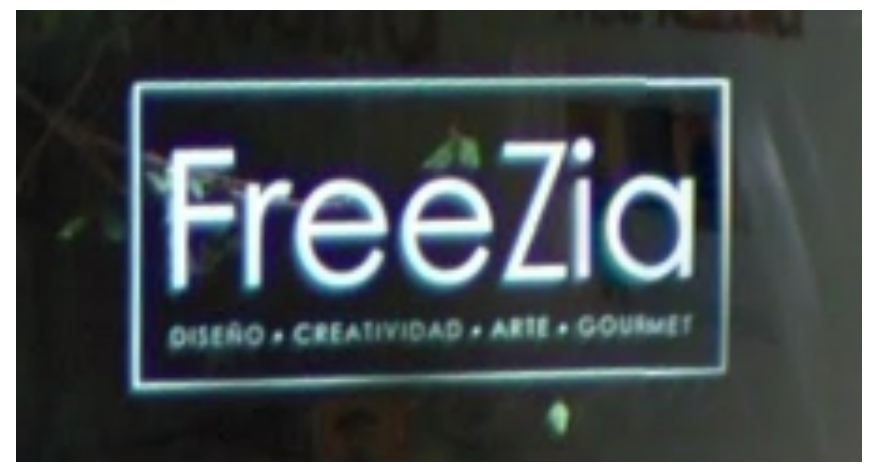

Con el fin de delimitar la zona de estudio, tras una cala inicial a través de la aplicación Google Street View se escogió el área topográfica que en 2008 presentaba una mayor presencia de signos que contenían lenguas de la migración, y se limitó el análisis a las calles Cuba, Denia, Puerto Rico, Pintor Gisbert, Buenos Aires, Literato Azorín y Sueca. En el Mapa 1 se muestra en negro la delimitación del barrio de Ruzafa y en rojo la zona estudiada.

\section{Mapa 1. Barrio de Ruzafa y zona estudiada. Fuente: Google Maps}

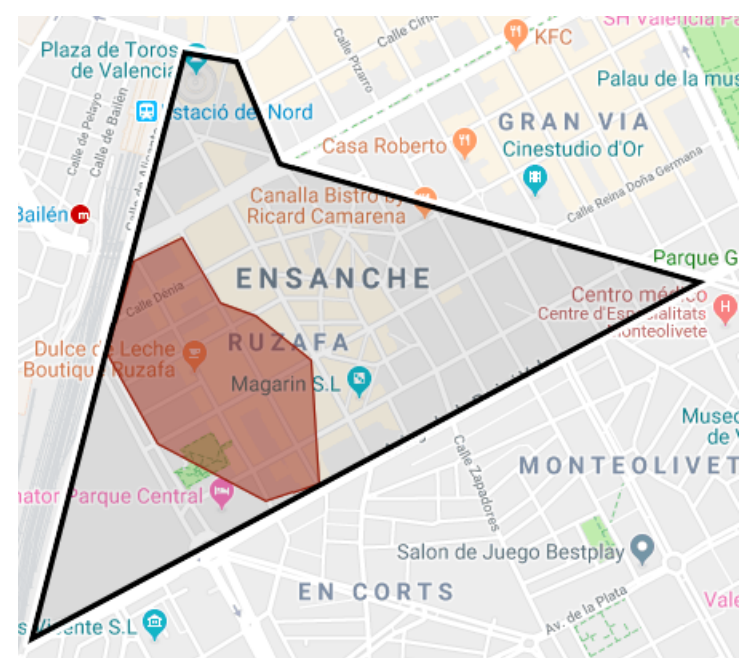

En cuanto a las herramientas utilizadas para obtener los signos que conforman nuestro corpus, se usaron principalmente Google Street View y Google Maps. El procedimiento seguido consistió en una primera delimitación desde Google Maps de la zona de Ruzafa que iba a ser analizada y una selección en esta misma aplicación de las calles que se iban a observar a continuación a través de Google Street View. Posteriormente se obtuvieron capturas de pantalla a partir de las imágenes de Google Street View que mostraban los rótulos de los comercios de las calles seleccionadas para el mapeo del estudio ${ }^{7}, y$, mediante la aplicación de una metodología cuantitativa, se

\footnotetext{
${ }^{7}$ Es importante apuntar que se han encontrado ciertas limitaciones en la recolección de datos por medio de Google Street View, que no obstante han podido subsanarse y no han afectado finalmente a los resultados del estudio. La aplicación presenta en ocasiones problemas técnicos como la baja calidad de imagen en algunos casos o la ilegibilidad de ciertos signos, que se han podido compensar ofreciendo una transcripción cuando era necesario. Otro problema es la presencia de obstáculos de visión (como árboles, farolas o
} 
organizaron y etiquetaron los signos del corpus. Los parámetros de la clasificación tuvieron en cuenta aspectos cronológicos, el año al que corresponde el signo, y espaciales, la calle en la que se encuentra el signo y del tipo de negocio al que pertenece el signo. Y en cuanto a las categorías de análisis (Backhaus, 2007) para nuestro estudio se han seleccionado: tipo de signo, lenguas en el signo, combinaciones de lenguas y prominencia visual o preferencia de código.

\section{RESULTADOS}

\subsection{CARACTERÍSTICAS GENERALES DEL CORPUS}

El corpus utilizado para este estudio está compuesto por un total de 212 fotografías de signos del PL, de las cuales 106 pertenecen al año 2008 y otras 106 al año 2018. Se han recogido los rótulos principales de los establecimientos que Google Street View permite ver con nitidez. Es importante tener en cuenta que, como muestra la Tabla 1, de las 106 imágenes del año 2018, 39 muestran signos en blanco, por lo que finalmente el total de signos analizados es de 173. Acuñamos en este trabajo el concepto de signos en blanco en el estudio del PL de carácter diacrónico-contrastivo para hacer referencia a aquellos signos que han desaparecido por cierre o abandono del comercio y que han dejado un vacío en su lugar.

Tabla 1. Datos generales del corpus

\begin{tabular}{|l|r|r|r|}
\hline \multicolumn{1}{|c|}{} & Fotografias & Signos & Signos en blanco \\
\hline $\mathbf{2 0 0 8}$ & 106 & 106 & 0 \\
\hline $\mathbf{2 0 1 8}$ & 106 & 67 & 39 \\
\hline Total & 212 & 173 & 39 \\
\hline
\end{tabular}

Con el fin de obtener una visión más completa de los signos estudiados, se ha recogido también información sobre el tipo de comercio con el que se corresponden los rótulos que conforman el corpus. Debido a la transformación que ha sufrido el barrio de Ruzafa en los últimos años, encontramos cambios en los tipos de comercios que llenaban las calles de este barrio de Valencia. Como se muestra en el gráfico 2, en el año 2008 predominaban los comercios dedicados a la venta de ropa y otros artículos de moda, así como las tiendas de alimentación, los restaurantes y los bazares. Sin embargo, en el año 2018 se observa que, de los signos recogidos, además de los que se corresponden con tiendas de alimentación y restaurantes, predominan los signos que pertenecen a comercios principalmente dedicados al ocio, el arte y la cultura, como galerías de arte o tiendas especializadas en fotografía, música o bellas artes. Esto podría considerarse un indicio del nuevo carácter cultural y moderno que ha adquirido el barrio como consecuencia del proceso de gentrificación.

vehículos) que impedían la captación de ciertos datos, que se solucionó mediante la obtención imágenes del año anterior o siguiente al seleccionado, siempre y cuando el signo no hubiera sufrido ningún cambio de contenido en el periodo de un año, así como con el cotejo visual a pie de calle cuando fue necesario. 


\section{Gráfico 2. Tipos de comercios en 2008 y 2018}

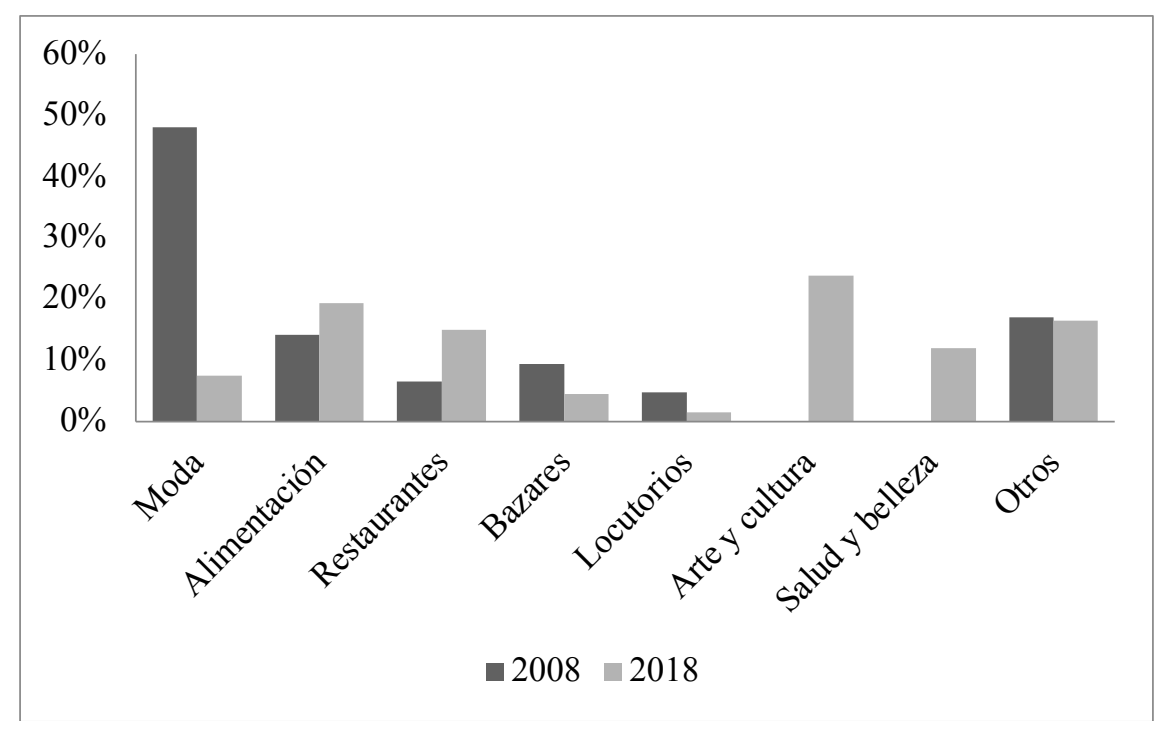

\subsection{TIPOS DE SIGNO Y LENGUAS EN EL SIGNO}

Durante el período examinado en el barrio de Ruzafa se han encontrado signos con un total de doce lenguas diferentes que son árabe, bambara, bereber, beya, chino, español, francés, inglés, lenguas indostánicas ${ }^{8}$, neerlandés, turco y valenciano. También se han recogido signos que contienen combinaciones o innovaciones lingüísticas a partir de una o más lenguas y que se han registrado bajo la etiqueta creaciones léxicas $^{9}$. A pesar de la dificultad que puede presentar la clasificación de este tipo de contenido, se ha considerado relevante contabilizar las creaciones léxicas, puesto que se suelen utilizar con cierta frecuencia en el PL urbano como nombres de algunos comercios por su carácter simbólico y evocador de otras lenguas, especialmente de lenguas que gozan de un mayor prestigio social a las que a partir de ahora llamaremos lenguas de prestigio, como el español, el inglés o el francés (apreciamos un ejemplo de creación léxica en la figura 2, que recuerda a las palabras freeze o free en inglés).

Según el número de lenguas presentes en los signos, diferenciamos entre signos monolingües, bilingües, trilingües y signos en blanco. Como indica el gráfico 3 , en el año 2008 el $82 \%$ de los signos del PL de la zona de Ruzafa analizada eran bilingües. Los signos restantes eran de tipo monolingüe $(10 \%)$ y trilingüe $(8 \%)$. No encontramos signos en blanco en el año 2008. Respecto a los signos del año 2018, como se refleja en el gráfico 4 , encontramos una mayor presencia de signos monolingües, que representan un $33 \% \mathrm{del}$ total. Los signos bilingües constituyen un $27 \%$ de los signos de 2018 , y solo un $3 \%$ son signos trilingües. Los signos restantes, que se corresponden con un $37 \%$, son signos en blanco. Este elevado porcentaje de signos en blanco se debe a la desaparición o el cierre de muchos de los comercios que antes pertenecían a personas migrantes y que marcharon del barrio por el encarecimiento de los alquileres.

\footnotetext{
${ }^{8}$ Las lenguas habladas en la región del Indostán están agrupadas en una misma categoría puesto que la mayoría de las palabras escritas en estas lenguas eran nombres propios originales del sánscrito comunes a varias de ellas.

${ }^{9}$ Se trata de signos ambiguos, como describe Pons (2012: 76): «Habrá también palabras que no pertenezcan a ninguna lengua concreta (creaciones surgidas de la fantasía de quien acuña una marca o el nombre de su propio comercio) o se pueden adscribir a varias lenguas como muestra de una estrategia comercial deliberadamente inclusiva (internacionalismos, también codificados como signos ambiguos por autores como Cenoz / Gorter 2006: 77 o Edelman 2010: 68)».
} 
Gráfico 3. Porcentaje de signos monolingües, bilingües y trilingües en 2008

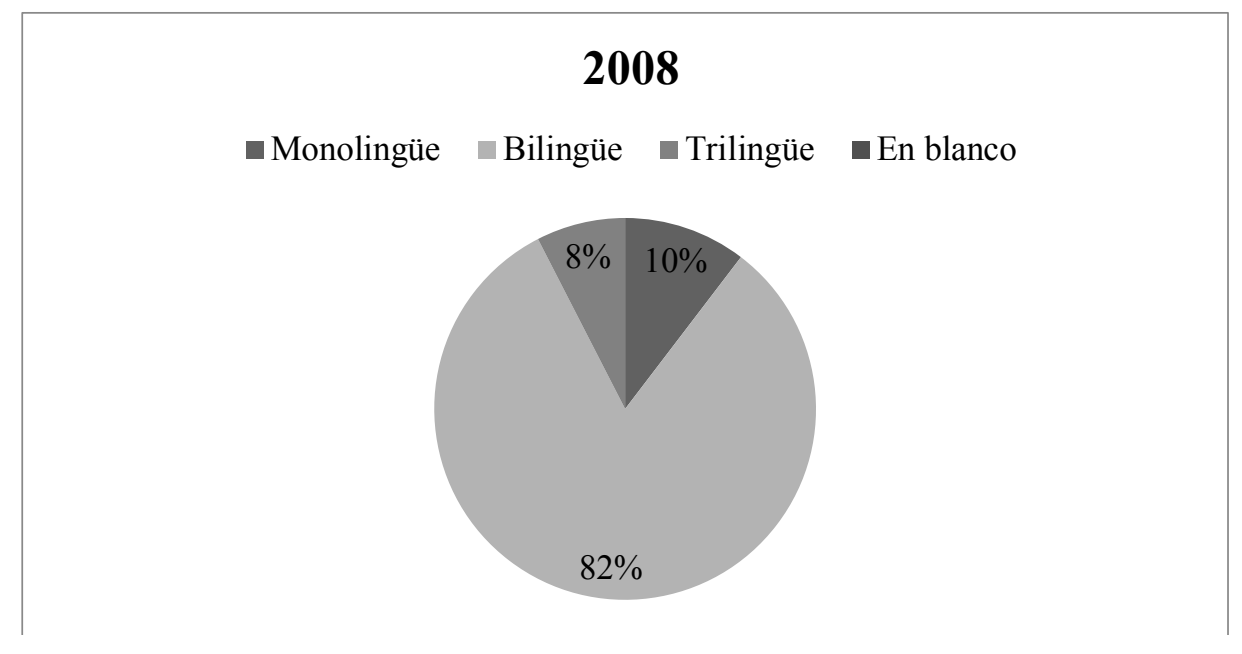

Gráfico 4. Porcentaje de signos monolingües, bilingües y en blanco en 2018

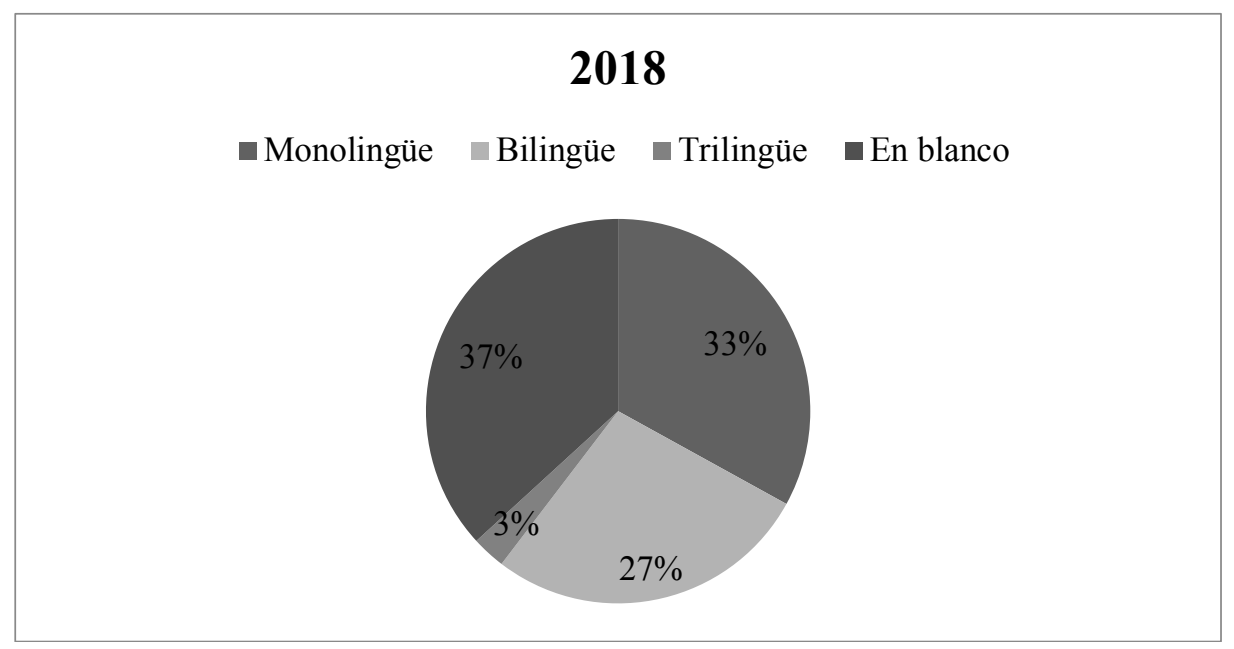

Además de conocer con qué frecuencia se da cada tipo de signo en el corpus, uno de los objetivos es analizar qué lenguas encontramos según el tipo de signo y cómo se combinan entre sí. En el gráfico 5 se muestran las lenguas que aparecen en los signos monolingües del año 2008 y 2018. Podemos apreciar que la mayoría de los signos monolingües en 2008 eran en español. No obstante, es difícil determinar en qué casos la autoría del signo es una persona migrante o no, puesto que el español, además de ser lengua de migración de las personas de origen hispanoamericano, es una de las lenguas maternas de gran parte de los habitantes de la ciudad de Valencia, y también es adoptada y utilizada por la población migrante no hispanohablante en sus rótulos. Dado que el interés principal del estudio son los signos generados por la población migrante, los signos monolingües en español que se han recogido son aquellos en los que se podía saber con certeza que el autor del signo o el propietario del comercio era de origen extranjero, ya que se hacía referencia explícitamente al origen extranjero del producto vendido. En la figura 3 encontramos un ejemplo de un signo monolingüe en español generado por una persona de origen migrante perteneciente a la comunidad latinoamericana. 


\section{Figura 3. Rótulo de un comercio donde se ofrecen productos de origen latinoamericano en la Calle Sueca, 19 (2018)}

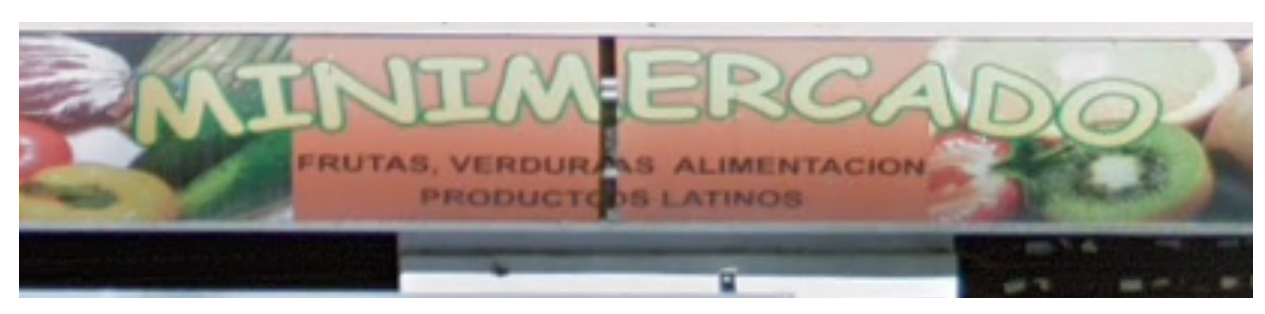

Diez años después el español sigue siendo la lengua de mayor frecuencia en los signos monolingües, frente a la ausencia total de signos monolingües en chino o en árabe. Según nuestros datos, los signos previos han sido reemplazados por una mayor presencia del inglés y por la aparición de lenguas que no existían en los signos monolingües del año 2008 , como el valenciano ${ }^{10}$, el francés y las creaciones léxicas derivadas de otras lenguas de prestigio. Debe tenerse en cuenta que el inglés que encontramos en el PL de 2018 no aparece ya prácticamente como una de las lenguas de migración, como sí que ocurría en 2008, dado que en algunos países de África o Asia (como Nigeria, Ghana, la India, etc.) de los que provenía parte de la migración el inglés es lengua oficial o cooficial, sino que en 2018 se encuentra en la mayoría de los casos como lengua de prestigio y símbolo de la modernización del barrio.

\section{Gráfico 5. Porcentaje de signos monolingües según lengua en 2008 y 2018}

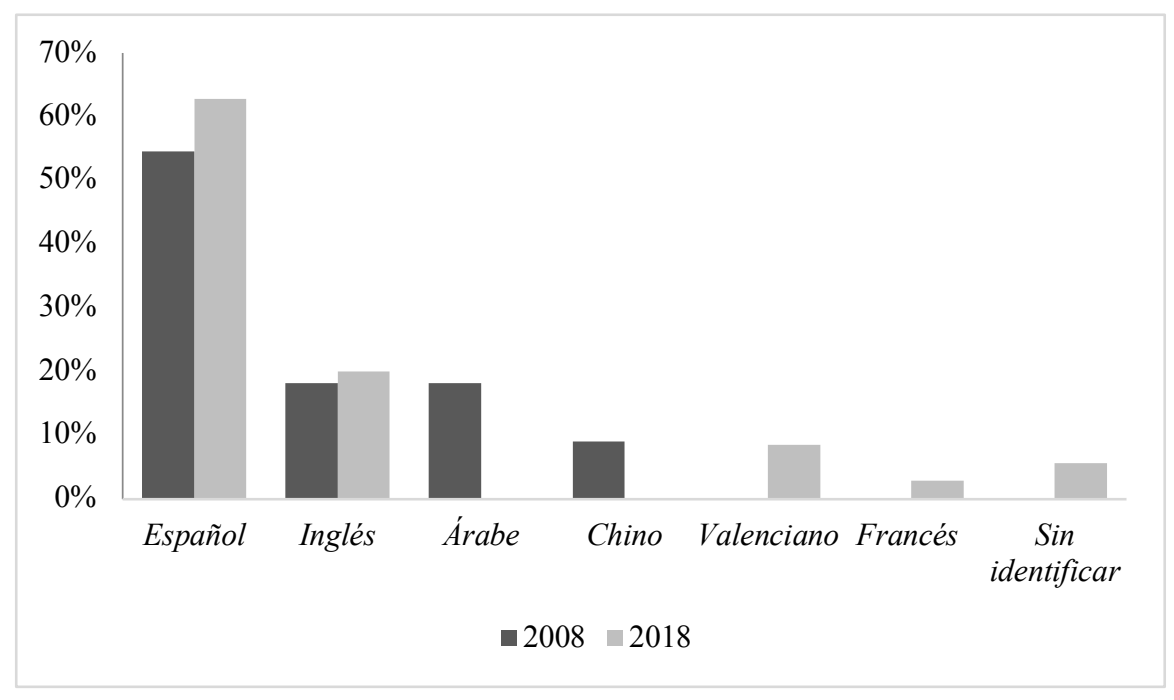

\footnotetext{
${ }^{10}$ La convivencia de las dos lenguas oficiales de la Comunidad Valenciana, especialmente en la ciudad de Valencia ha sido abordada por Vallés (2003) y por Lado (2011) como reflejo de un conflicto lingüístico. Bellés-Calvera (2019) confirma que «The findings also indicate that the power of the two co-official languages is reinforced by public signs, whereas rich linguistic diversity is shown in private signs». Es curioso que el valenciano reaparezca en el PL del barrio, puesto que de un barrio modernizado como Ruzafa cabría esperar que esta lengua, minoritaria en nuestros datos, se viera reemplazada por otras lenguas de prestigio. No obstante, se atisba un intento de reintroducir el valenciano en el PL de Ruzafa y tal vez de recuperar de algún modo la esencia tradicional de esta zona de la ciudad, con lo que adquiriría así un valor simbólico más que meramente informativo o de lengua de uso.
} 
Asimismo, nos interesa saber cómo se presenta la combinación de las diferentes lenguas (gráfico 6). Cabe destacar que en todos los signos bilingües encontramos el español como lengua que se combina con otras. La combinación más frecuente en 2008 es la de español-chino, que representa un $60 \%$, seguida de español-árabe y, en menor porcentaje, español-inglés, español-indostánico, español-bereber y español-beya. En los signos bilingües del año 2018 encontramos nuevas combinaciones que se añaden a las que ya aparecían diez años atrás, como las combinaciones español-valenciano, españolturco y español-creación léxica. Debido a los cambios en la población migrante china del barrio de Ruzafa, los resultados son similares a los encontrados por Ma (2019): la combinación español-chino ya no es la más repetida, sino que se encuentra por debajo de las combinaciones español-árabe y español-inglés, que es la segunda más frecuente. Vemos pues, que el inglés goza de una mayor presencia en los signos bilingües del año 2018 que en los del 2008.

Gráfico 6. Porcentaje de signos bilingües que contenían las diferentes combinaciones de lenguas en 2008 y 2018

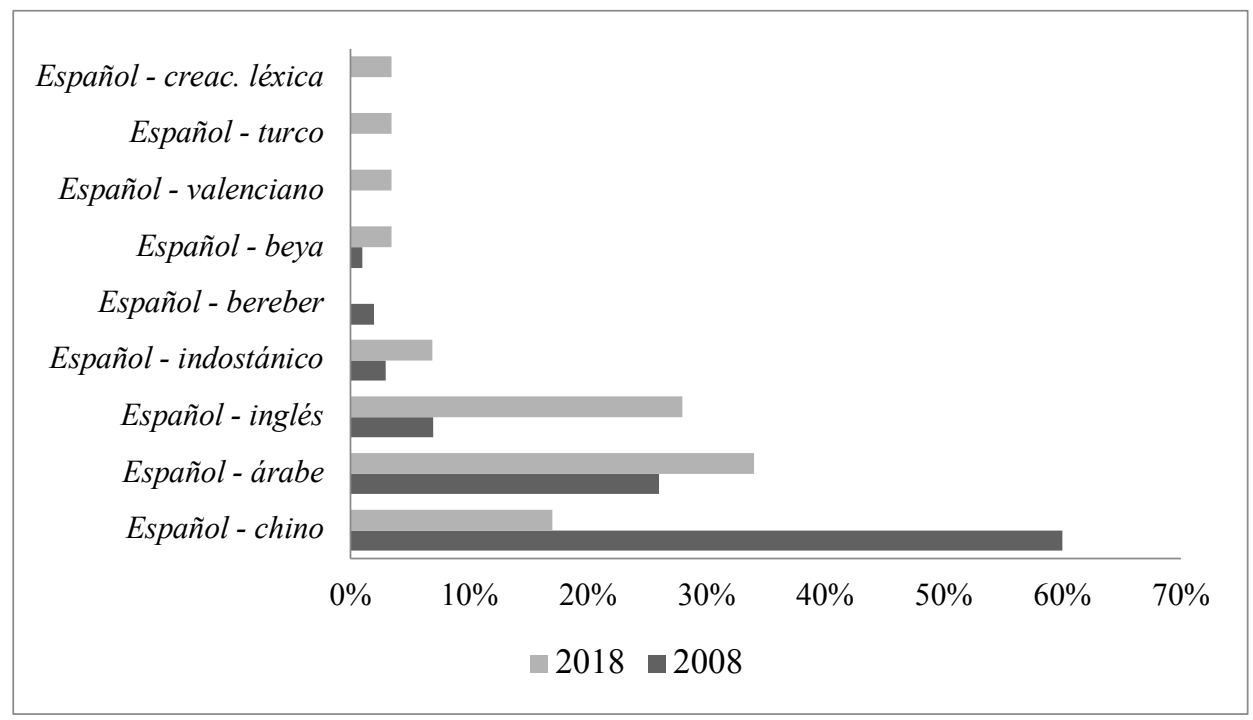

Advertimos también que algunos signos bilingües español-árabe se han mantenido en 2018. No obstante, esto no significa que no haya habido cambios: en las siguientes imágenes (figuras 4 y 5) observamos un ejemplo de un restaurante marroquí cuyo rótulo en 2008 contenía la palabra restaurante en español, así como el nombre propio Zakaria en lengua árabe transcrita al alfabeto latino, y alguna información complementaria en lengua y escritura árabe. Sin embargo, aunque en 2018 el signo continúa siendo bilingüe (ya que contiene el nombre propio Zakaria), el texto en escritura árabe ha sido sustituido y la cantidad de información en español ha aumentado. Es importante señalar que los signos que contenían información en español y nombres propios extranjeros se han etiquetado como bilingües, siguiendo la propuesta de Edelman (2009): «A researcher who does not code proper names as foreign languages gets an incomplete picture of the LL's multilingual character. Moreover, the possibility of the translation of names, however limited, shows that names can sometimes be part of specific languages». Es muy probable que la autoría del signo de 2008 y del signo de 2018 sea la misma y que, la persona migrante de origen marroquí que conserva el negocio sea quien ha tomado esta decisión. Este ejemplo, junto con otros similares que se recogen en el corpus, cabe interpretarse no 
solo como un cambio en el PL del barrio, sino también en las actitudes lingüísticas de sus habitantes. En el ejemplo comentado, el cambio en el rótulo del negocio en 2018 muestra una actitud lingüística de apertura hacia la comunidad externa de personas hispanohablantes.

Figura 4. Restaurante marroquí en la calle Puerto Rico, 26 (2008). Se ofrece información en árabe sobre la venta de productos 'halal acreditado'

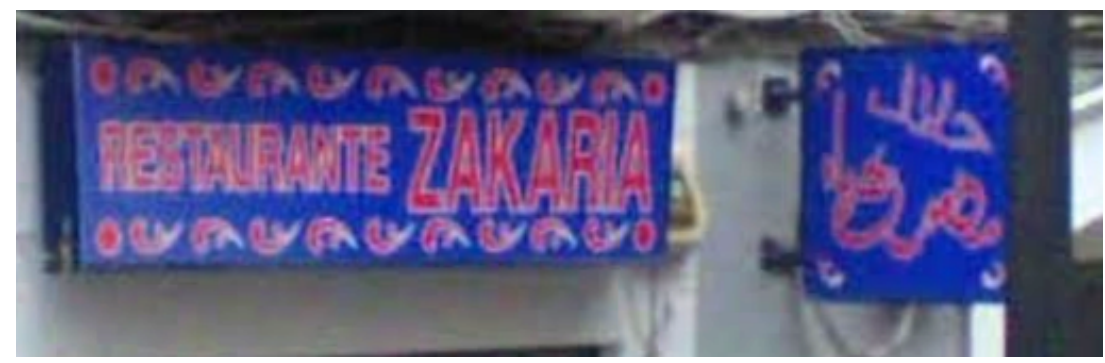

Figura 5. Nuevo rótulo para el Restaurante tetería Zakaria de comida marroquí en la calle Puerto Rico, 26 (2018)

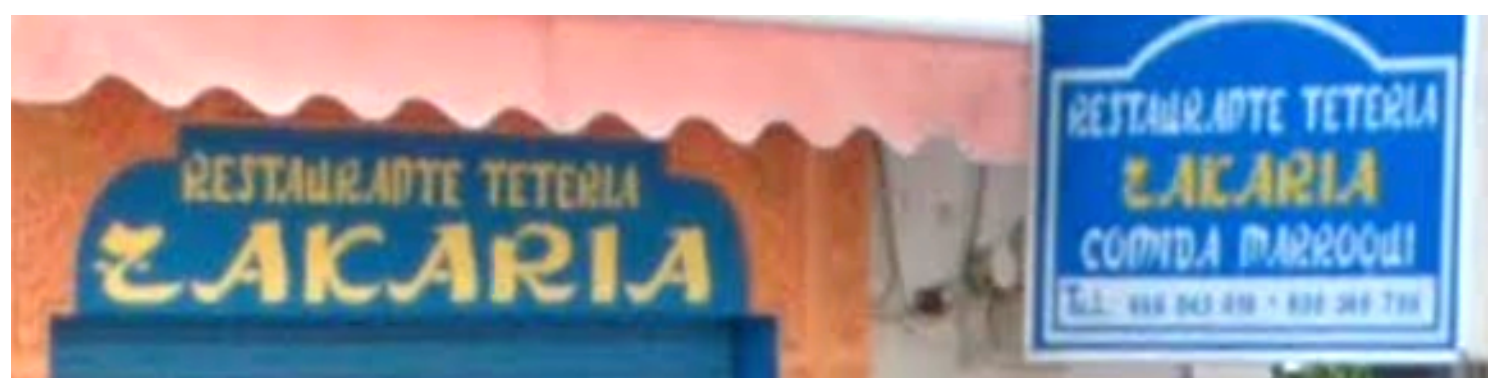

\subsection{PROMINENCIA VISUAL Y LENGUAS PROMINENTES}

Además de las lenguas que aparecen en los signos y de cómo se combinan entre sí, hemos indagado acerca de la prominencia visual en las lenguas de los signos del PL, concepto que Pons (2012: 72) define como «la capacidad del signo para atrapar la atención de quien lo ve a través de rasgos como el texto, el tamaño de la fuente, el colorido y la posición relativa que ocupa cada lengua, en el caso de que el mensaje no sea monolingüe». El estudio de la prominencia visual de las lenguas en los diferentes casos puede revelarnos las preferencias y actitudes lingüísticas de quienes elaboran los rótulos de sus comercios. No obstante, este rasgo no siempre se puede determinar fácilmente y por lo tanto, solo se han etiquetado como casos de prominencia visual aquellos signos en los que la presencia de este fenómeno era evidente (figuras 6 y 7). Hemos considerado qué lenguas son más prominentes frente a las otras en los signos de 2008 y 2018. En el gráfico 7 observamos que, en ambos momentos, en la mayoría de los signos bilingües y trilingües con prominencia, el español era la lengua que visualmente más atraía la atención. No obstante, resulta llamativo que, así como en 2008 encontrábamos 24 signos con el chino como lengua más prominente visualmente (un $34 \%$ de los signos con prominencia de ese año) como en el ejemplo de la figura 6, en 2018 no se ha registrado ningún caso similar en nuestro corpus. De nuevo comprobamos que en 2018 el español y en menor medida el inglés, ambas lenguas de prestigio, han ido imponiéndose sobre las lenguas de la migración y son ahora no solo las que aparecen con mayor frecuencia, sino también las que más captan la atención de los viandantes de Ruzafa (figura 7). Es 
interesante no solo la aparición del valenciano en los signos de 2018, como comentábamos anteriormente, sino también que se presente como la lengua más prominente visualmente en un $10 \%$ de los signos con prominencia de ese año frente al español.

Figura 6. Calle Cuba, 49. Comercio de prendas de vestir al por mayor, Lu Wang Li S. L., pidying del nombre inferior en caracteres chinos (2008)

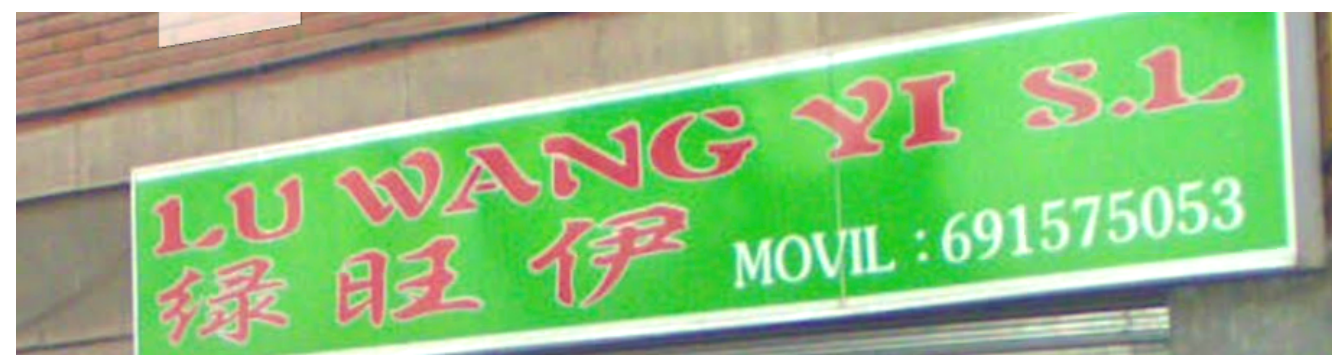

Figura 7. Calle Cuba, 49 (2018)

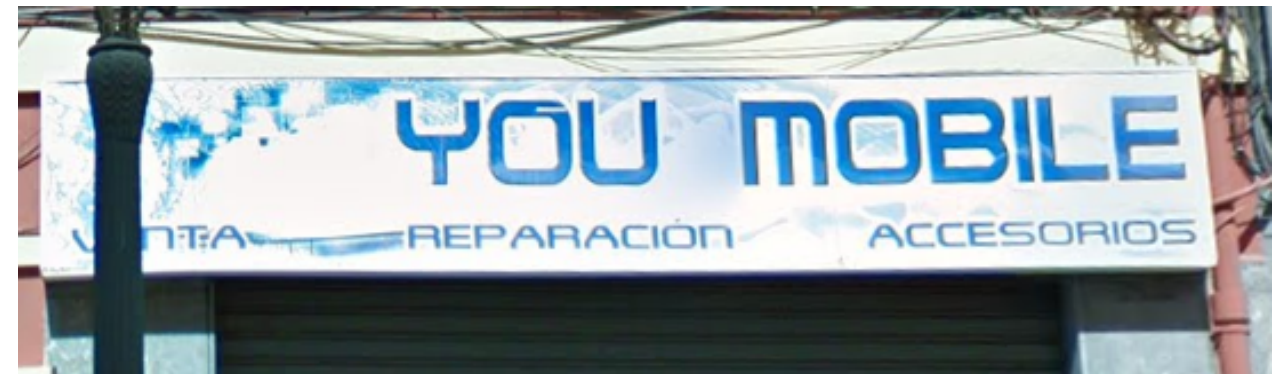

Gráfico 7. Porcentaje de signos con mayor prominencia visual en cada lengua en los años 2008 y 2018

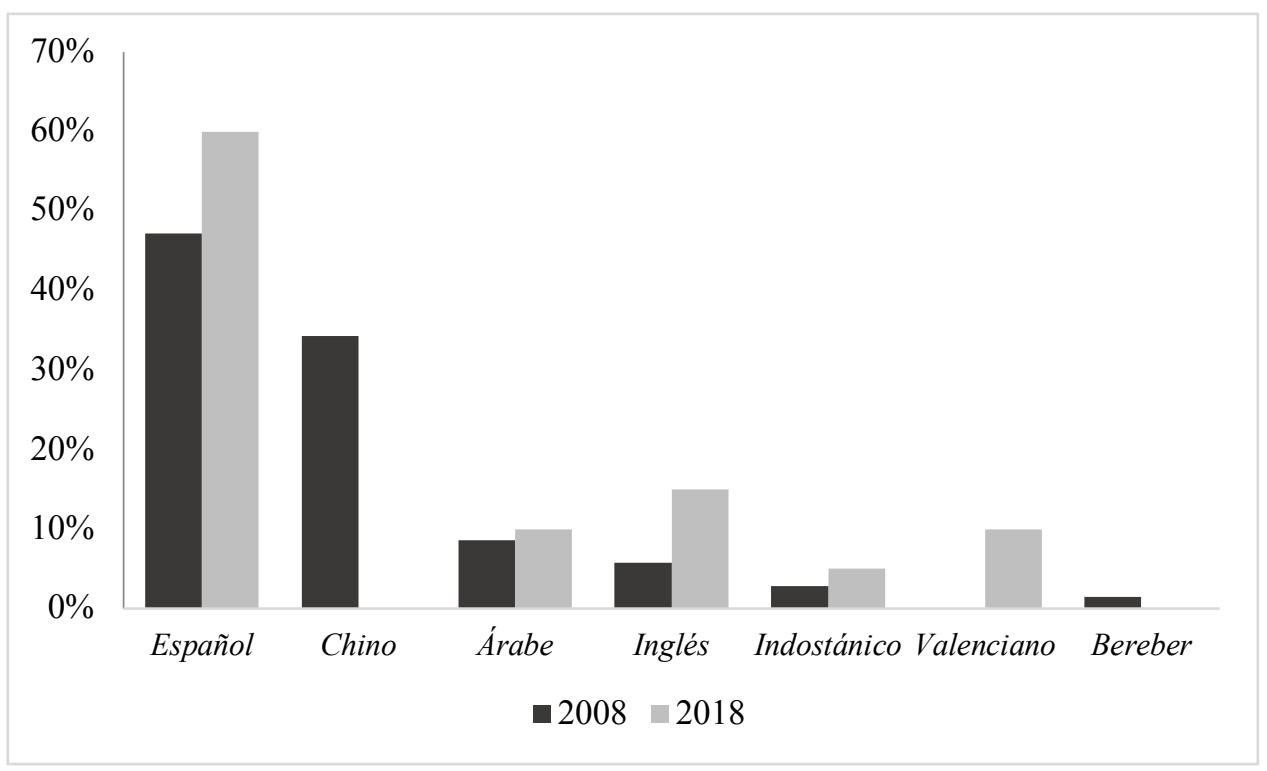

\section{CONSIDERACIONES FINALES}

Los datos recogidos para este estudio y los resultados obtenidos a partir de nuestro corpus indican que se han producido una serie de cambios en los signos analizados y, 
como consecuencia, una transformación en el PL de la zona estudiada, que responde a la vitalidad y el cambio consustancial a toda indagación sobre los espacios urbanos compartidos por comunidades etnolingüísticas diversas. Basándonos en los resultados obtenidos podemos concluir que, efectivamente, el paso del tiempo ha provocado una transformación en el PL de Ruzafa. Lo interesante es, sin embargo, plantearse qué tipo de cambios se han dado en este barrio y cuál es el factor principal que ha motivado esta transformación del PL en esta zona de Valencia. Es decir, no sería suficiente explicar que estos cambios son simplemente una consecuencia más del paso de los años, sino que debemos preguntarnos qué ha sucedido en ese período para que se dé esta transformación en el barrio, no solo a nivel social, económico o demográfico, sino también a nivel lingüístico. La aplicación de un enfoque diacrónico a este estudio de PL, así como el uso de la herramienta Google Street View y la elaboración de un corpus de signos del PL de Ruzafa, nos ha permitido responder a esta pregunta.

Conociendo los fenómenos socioeconómicos que han afectado profundamente al barrio, como la llegada de un importante número de personas migrantes a partir de los años 80 y la posterior gentrificación de Ruzafa, podemos establecer una conexión entre estos procesos y los cambios lingüísticos en el barrio. Hemos observado en los datos extraídos de nuestro corpus que en 2008 la mayoría de los signos del PL de la migración eran bilingües, pues combinaban el español con otras de la migración, como el chino, el árabe o el inglés. Esta combinación de la lengua del país de acogida con la lengua del país de origen en los signos de sus negocios, además de indicar un elevado grado de actividad comercial por parte de personas migrantes en el barrio, puede ser un indicio de la actitud positiva hacia el español y de la intención de integración por parte de los autores de los signos, que por un lado conservaban una parte de su cultura mostrando su lengua nativa en los rótulos de sus comercios, y al mismo tiempo trataban de establecer una comunicación con los nativos del barrio aportando información en español. Por otra parte, en 2018 observamos que el grado de frecuencia de signos bilingües ha disminuido considerablemente en los últimos años y ha dado lugar a un PL constituido en gran medida por signos monolingües. Asimismo, no solo se advierte un descenso en la frecuencia de uso las lenguas de la migración que aparecían en 2008, sino que además hemos comprobado que visualmente también han pasado a un segundo plano, como refleja el análisis de la prominencia visual de las diferentes lenguas.

Así pues, comprobamos que se ha perdido parte de la riqueza lingüística que se podía encontrar en el barrio en el año 2008, pues ya no encontramos tanta diversidad de lenguas en su PL, sino que las lenguas de los migrantes que residían y llevaban a cabo su actividad comercial en las calles de Ruzafa han ido siendo sustituidas por lenguas consideradas de mayor prestigio como el español y el inglés, en sintonía con el carácter moderno y turístico que ha ido adquiriendo el barrio desde que comenzó su proceso de gentrificación.

Con todo ello, podemos concluir que las consecuencias del proceso de gentrificación residencial, comercial y cultural que ha sufrido Ruzafa desde 2008 no han sido únicamente la modernización, el enriquecimiento el barrio y el aumento de su atractivo turístico, sino que también ha provocado el desplazamiento de la población migrante que se había establecido en Ruzafa y se había integrado en la vida del barrio, y con ello, en cierto modo, la pérdida de su auténtico carácter multicultural. Es cierto que todavía encontramos lenguas extranjeras en esta área de Valencia, pero tras haber observado el pasado de Ruzafa como barrio de inmigración, nos planteamos si esta imagen de barrio multicultural que tenemos de la Ruzafa actual no es sino una simple ilusión. Ahora las lenguas extranjeras que encontramos en las calles son, en la mayoría de los casos, un reclamo para turistas o para aquellos ciudadanos que buscan ambientes 
más modernos. Sin embargo, como hemos comprobado a partir de observación del PL de la Ruzafa del 2008 y de la conversación con vecinos que conocen el barrio desde hace décadas, lo que encontrábamos en las calles de este barrio en esos años era un verdadero intercambio cultural entre personas procedentes de diversos contextos étnicos y lingüísticos que convivían en armonía y enriquecían el paisaje lingüístico de nuestra ciudad.

\section{REFERENCIAS BIBLIOGRÁFICAS}

Ariolfo, Rosana y Mariottini, Laura (eds.). 2018. «Paisajes lingüísticos de la migración. Contextos mediáticos, urbanos y formativos». Lingue e linguaggi, 25: 5-15. http://siba-ese.unisalento.it/index.php/linguelinguaggi/article/view/18956

Ajuntament de València. 2018. «Estadísticas por territorio: Barrios». Oficina de estadística.

http://www.valencia.es/ayuntamiento/webs/estadistica/inf_dtba/2018/Distrito_02 Barrio_1.pdf

Backhaus, Peter. 2006. "Multilingualism in Tokyo: A Look into the Linguistic Landscape». International Journal of Multilingualism, 3: 52-66. https://www.degruyter.com/view/j/ijsl.2005.2005.issue-175176/ijsl.2005.2005.175-176.103/ijsl.2005.2005.175-176.103.xml?format=INT

Backhaus, Peter. 2007. Lingüistic Landscapes: A Comparative Study of Urban Multilinguism in Tokyo. Clevedon / Buffalo / Toronto: Multilingual Matters.

Bellés-Calvera, Lucía. 2019. «The Linguistic Landscape of the Valencian Community: A Comparative Analysis of Bilingual and Multilingual Signs in Three Different Areas». Languages, 4(2): 38. https://doi.org/10.3390/languages4020038

Ben-Rafael, Eliezer, Elana Shohamy, Muhammad Hasan Amara y Nira Trumper-Hecht. 2006. «Linguistic Landscape as Symbolic Construction of the Public Space: the Case of Israel». International Journal of Multilingualism, 3(1): 7-30.

Blommaert, Jan. 2013. Ethnography, Superdiversity and Linguistic Landscapes: Chronicles of Complexity. Bristol / Buffalo / Toronto: Multilingual Matters.

Bruyèl-Olmedo, Antonio y María Juan-Garau. 2020. "Coexisting varieties of English in the linguistic landscape of tourism: The Bay of Palma». Journal of Multilingual and Multicultural Development, 41(2): 157-174. https://www.tandfonline.com/doi/abs/10.1080/01434632.2019.1606226?journal Code $=$ rmmm 20

Calvi, Maria Vittoria. 2018. «Paisajes lingüísticos hispánicos: panorama de estudios y nuevas perspectivas». Lynx. Panorámica de Estudios Lingüísticos, 17: 5-58.

Calvo, Julio. 2007. Tendiendo puentes. La lengua de los emigrantes peruanos (y ecuatorianos) en la Comunidad Valenciana. Valencia: Universidad de Valencia.

Castillo Lluch, Mónica y Daniel Sáez Rivera. 2011. «Introducción al paisaje lingüístico de Madrid». Lengua y migración, 3(1): 73-88. http://lym.linguas.net/Download.axd?type=ArticleItem\&id=89

Castillo Lluch, Mónica y Daniel Sáez Rivera (eds.). 2013. «Paisajes lingüísticos en el mundo hispánico». Revista Internacional de Lingüística Iberoamericana RILI, 11(1).

Castillo Lluch, Mónica. 2019. «Reading diachrony in Linguistic Landscape synchrony: Spanish in Lausane». En Linguistic Landscape Studies. The French Connection, eds. Castillo Lluch, Mónica, Rolf Kailuweit y Claus D. Pusch. Freiburg / Berlin / Wien: Rombach Verlag. 
Cenoz, Jasone y Durk Gorter. 2006. «Linguistic Landscape and Minority Languages». En Linguistic Landscape: New Approach to Multilingualism, ed. Gorter, Durk. Clevedon / Buffalo: Multilingual Matters.

Comajoan, Llorenç. 2013. «El paisaje lingüístico en Cataluña: caracterización y percepciones del paisaje visual y auditivo en una avenida comercial de Barcelona». Revista internacional de lingüistica Iberoamericana, 11(1): 63-88.

Edelman, Loulou. 2009. "What's in a name? Classification of Proper Names by Language». En Linguistic landscape: expanding the scenery, eds. Gorter, Durk y Elana Shohamy. Nueva York: Routledge.

Esteba Ramos, Diana. 2014. «Aproximación del paisaje lingüístico de Málaga: préstamos y reflejos de una realidad lingüística plural». Recherches, 12: 165-187.

Félez Vicente, María. 2017. «El paisaje lingüístico de Zaragoza a través de los barrios de La Magdalena y El Gancho». Archivo de Filología Aragonesa, 73: 203-233. https://ifc.dpz.es/recursos/publicaciones/36/72/08felezvicente.pdf

Fernández Juncal, Carmen. 2019. «Paisaje lingüístico urbano y rural: parámetros de caracterización». Cultura, lenguaje y representación, 21: 41-56. http://www.erevistes.uji.es/index.php/clr/article/view/3585/3133

Franco Rodríguez, José M. 2013. «An alternative reading of the linguistic landscape: the case of Almería». Revista internacional de lingüística hispánica, 11(1): 109-135.

Guilat, Yael y Antonio B. Espinosa-Ramírez. 2016. «The Historical Memory Law and its role in redesigning semiotic cityscapes in Spain: A case study from Granada». Linguistic Landscape: An International Journal, 2(3): 247-274. https://doi.org/10.1075/11.2.3.03gui

Gorter, Durk. 2013. «Linguistic landscapes in a multilingual world». Annual Review of Applied Linguistics, 33: 190-212. https://doi.org/10.1017/S0267190513000020

Gorter, Durk. 2018. «Methods and techniques for Linguistic Landscape research: About definitions, core issues and technological innovations». En Expanding the Linguistic Landscape. Linguistic diversity, multimodality and the use of space as semiotic resouce, eds. Pütz, Martin y Neele Mundt. Bristol: Multilingual Matters.

Gorter, Durk y Jasone Cenoz. 2017. «Linguistic Landscape and Multilingualism». En Language Awareness and Multilingualism, eds. Jasone Cenoz, Durk Gorter y Stephen May. Encyclopedia of Language and Education. Cham, Switzerland: Springer.

Hong, Seong-Yun. 2020. «Linguistic Landscapes on Street-Level Images». ISPRS International Journal of Geo-Information, 9: 57. https://doi.org/10.3390/ijgi9010057

Lado, Beatriz. 2011. «Linguistic landscape as a reflection of the linguistic and ideological conflict in the Valencian Community». International Journal of Multilingualism, 8(2): $135-150$.

Landry, Rodrigue y Richard Bourhis. 1997. «Linguistic Landscape and Ethnolinguistic Vitality: An Empirical Study». Journal of Language and Social Psychology, 16(1): 23-49. https://journals.sagepub.com/doi/pdf/10.1177/0261927X970161002

Ma, Yujing. 2017. «El paisaje lingüístico chino-español de la ciudad de Valencia: una aproximación a su estudio». Lengua y migración, 9(1): 63-84. http://lym.linguas.net/Download.axd?type=ArticleItem\&id=173

Ma, Yujing. 2019. El paisaje lingüístico chino-español en la ciudad de Valencia y su aplicación a la enseñanza de ELE a sinohablantes. Tesis Doctoral. Valencia: Universitat de València. http://roderic.uv.es/handle/10550/72244 
Miquel Bartual, Mijo. 2016. «La manzana perdida de Russafa: estrategias de autogestión frente a procesos de gentrificación». Kultur. Revista interdisciplinària sobre la cultura de la ciutat, 3(5): 155-175. http://www.e-revistes.uji.es/index.php/kultur/article/view/7/1868

Moreno Fernández, Francisco. 2009. «Integración sociolingüística en contextos de inmigración: marco epistemológico para su estudio en España». Lengua y migración, 1(1): 121-156. http://lym.linguas.net/Download.axd?type=Article

Moustaoui, Adil. 2013. «Nueva economía y dinámicas del cambio sociolingüístico en el paisaje lingüístico de Madrid el caso del árabe». Revista internacional de lingüistica iberoamericana, 11(1): 89-108.

Muñoz Carrobles, Diego. 2013. Lenguas y culturas en contacto en contexto urbano: el caso de la comunidad rumana de Madrid. Tesis doctoral. Madrid: Universidad Complutense de Madrid. https://eprints.ucm.es/18102/1/T34230.pdf

Muñoz Carrobles, Diego. 2010. «Breve itinerario por el paisaje lingüístico de Madrid». Revista de estudios sobre la ciudad como espacio plural, 2(2): 103-109. http://www.ucm.es/info/angulo/volumen/Volumen02-2/varia04.htm

Pons Rodríguez, Lola. 2012. El paisaje lingüistico de Sevilla. Lenguas y variedades en el escenario urbano hispalense. Sevilla: Diputación de Sevilla.

Pons Rodríguez, Lola. 2011. «Hispanoamérica en el paisaje lingüístico de Sevilla». Revista Itinerarios, 13: 97-129. http://itinerarios.uw.edu.pl/hispanoamerica-enel-paisaje-linguistico-de-sevilla

Regueira, Xosé Luis, Miguel López Docampo y Matthew Wellings. 2013. «El paisaje lingüístico en Galicia». Revista Internacional de Lingüística Iberoamericana. 11(1): 39-62.

Romero Renau, Luis y Laura Lara Martín. 2015. «De barrio-problema a barrio de moda: gentrificación comercial en Russafa, el "Soho" valenciano». Anales de geografia de la Universidad Complutense, 35(1): 187-212. https://revistas.ucm.es/index.php/AGUC/article/view/48969

Rosa, Krzysztof Piotr. 2016. La influencia del turismo en el paisaje lingüístico de la ciudad de Valparaíso: un estudio empírico. Trabajo final de máster. Nimega: Radboud Universiteit. https://theses.ubn.ru.nl/handle/123456789/3822

Sáez Rivera, Daniel M. y Mónica Castillo Lluch. 2012. "The Human and Linguistic Landscape of Madrid (Spain)». En Linguistic Landscapes, Multilingualism and Social Change, eds. Bagna, Carla, et al. Frankfurt am Main: Peter Lang.

Spolsky, Bernard. 2009. «Prolegomena to a sociolinguistic theory of public signage». En Linguistic Landscape: Expanding the scenery, eds. Shohamy, Elana y Durk Gorter. New York: Routledge.

Torres Pérez, Francisco. 2006. «Las dinámicas de la convivencia en un barrio multicultural. El caso de Russafa (Valencia)». Papeles del CEIC, International Journal on Collective Identity Research, 1(23). http://www.ehu.eus/ojs/index.php/papelesCEIC/article/view/12183

Torres Pérez, Francisco. 2007. Nous veïns a la ciutat. Els emigrants a València i Russafa. Valencia: Publicacions de la Universitat de València.

Troyer, Robert A. y Tamás Péter Szabó. 2017. «Representation and videography in linguistic landscape». Linguistic Landscape, 3 (1): 56-77. https://doi.org/10.1075/11.3.1.03tro

Vallès Sanchis, Ismael. 2003. «Aproximació a la imatge lingüística de la ciutat de València». Cuadernos de Geografia, 73/74: 391-400. https://www.uv.es/cuadernosgeo/CG73_74_391_400.pdf 
Van Mensel, Luk, Mieke Vandenbroucke y Robert Blackwood. 2016. «Linguistic landscapes». En The Oxford Handbook of language and society, eds. Garcia, Ofelia, Max Spotti y Nelson Flores. Oxford: Oxford University Press.

Zimmermann, Klaus y Laura Morgenthaler García. 2007. «¿Lingüística y migración o lingüística de la migración?: De la construcción de un objeto científico hacia una nueva disciplina». Revista Internacional de Lingüistica Iberoamericana, 5(10): $7-19$. 